\title{
The infra-optic course of the anterior cerebral arteries: an anatomical case report
}

\author{
Cüneyt Bozer · Osman Barış Öztürk · Hasan Ozan
}

Received: 3 July 2008 / Accepted: 14 August 2008 / Published online: 13 September 2008

(C) Springer-Verlag 2008

\section{Dear Sir,}

We have read with considerable interest the article by Peltier et al. on the infra-optic course of the anterior cerebral arteries. Since we have seen some mistakes, we would like to comment on figures and legends of the paper by Peltier et al. [2].

According to the classical anatomical textbooks and atlases, there is a confusion in legends of the figures [1,35]. In Figure 1, the connection between posterior cerebral artery and the artery named $\mathrm{rPcoA}$ has not been pointed out. At the caudal side, lumen of the rPcoA can be seen and this artery should be the right internal carotid artery. In our opinion, the smaller arterial branch coursing over the posterior perforated substance medial to the right internal carotid artery is $\mathrm{rPcoA}$. The artery right caudal to the 1AchA should be the left posterior communicating artery.

Since the AchA is a branch of internal carotid artery, the artery named AcoA should be the internal carotid artery in
Figure 2. But if we accept the legend AcoA as it is true, then the artery named McA should be the right anterior cerebral artery.

In our opinion, the correction of these legends will make the article more comprehensible.

\section{References}

1. Netter FH (1997) Atlas of human anatomy, 3rd edn. Icon Learning Systems, New Jersey

2. Peltier J, Fichten A, Havet E, Page C, Foulon P, Laude M, Le Gars D (2007) The infra-optic course of the anterior cerebral arteries: an anatomic case report. Surg Radiol Anat 29(5):389-392

3. Putz R, Pabst R (eds) (2001) Sobotta. $f$ Atlas of human anatomy, 13th edn. Lippincott Williams \& Wilkins, Philadelphia

4. Rohen JW, Yokochi C, Lütjen-Drecoll E (1998) Color atlas of anatomy, 4th edn. Lippincott Williams \& Wilkins, Philadelphia

5. Williams PL (1995) Gray's anatomy, 38th edn. Churchill Livingstone, London
C. Bozer $(\bowtie)$

Department of Anatomy, Faculty of Medicine,

Trakya University, Güllapoğlu Campus,

22030 Edirne, Turkey

e-mail: cuneytbozer@trakya.edu.tr

O. B. Öztürk

Department of Anatomy, Faculty of Medicine,

Düzce University, Konuralp Campus,

81620 Düzce, Turkey

H. Ozan

Department of Anatomy, Faculty of Medicine,

Gülhane Military Medical Academy,

GATA Komutanlığı, Etlik, 06018 Ankara, Turkey 